\title{
A Research on the Dilemma in China's Emission Trading System and Relevant Countermeasures
}

\author{
Shumao Zhang \\ Industrial and Commercial Management College, Shenyang University, Shenyang 110044, China \\ School of Economics, Liaoning University, Shenyang 110036, China \\ E-mail: zsm0410@163.com
}

\begin{abstract}
s
With the constantly rapid economic development in China, the environmental issue seems increasingly prominent and the conflicts between waste emission and China's current emission trading system become more fierce. In spite of the active explorations in emission trading system in China in the recent years, there are still a lot of problems, including the difficulty in confirming the environmental capacity, imperfect market system and incomplete law and so on. Therefore, it is quite urgent to perfect China's emission trading system in terms of legislation, market trading system, government administration and so on.
\end{abstract}

Keywords: Emission trading, Market system, Administration

Emission trading, a market-based environmental policy tool by nature, encourages environmental subjects to take measures through market signals and finally leading to the reduction of emission while promoting enterprises and individuals to pursue their self-interest instead of laying down definite emission reduction tasks or methods. Up to now, emission trading system has been attached great importance to throughout the world as well as converted into reality from a simple concept in some western developed nations. Therefore, an analysis on emission trading system is of both academic value and practical significance.

\section{Theoretical Basis for Emission Trading}

In traditional economy, based on externality, environmental policy burdens the enterprises producing pollution with all the external cost of environmental pollution in the form of taxation, subsidy elimination and deposit system. But this method increases the government's chances of rent-seeking, hence failing to achieve ideal goals in the practical application to solve environmental problems since it is impossible to realize Pareto optimum in resources allocation through emission trading system. Based on Coase Theorem, the basic idea of this theory is that it also takes social cost to prohibit pollution and therefore the key to the design of the system should be how to reduce the social cost and realize the optimization of resources allocation.

According to Coase Theorem, under the circumstances of unclear environmental capacity ownership, an inconsistency between private cost and social cost will be caused during enterprises' employment of environmental capacity with the increased degree of environmental capacity insufficiency as well as higher relative price, hence leading to some other problems. With perfect market system, efficiency loss caused by external problems can be solved through the negotiation system, the price system and the free competition system of the market itself as long as the ownership is clearly defined and protected, that is, to spontaneously form a emission trading market to compensate for the victim's loss and to solve the adverse effect of environmental pollution on economy. Therefore, pollution can be solved and social welfare can be optimized naturally with definite ownership and perfect market system. Actually, emission trading system is an application of Coase Theorum to practice.

\section{China's Laws, Policies and Practice Related to Emission Trading}

\subsection{Laws and Institutions on Emission Trading}

Currently, China's emission still lies at the trial stage. In some areas, some local laws and regulations on emission trading have been issued in sequence, such as Regulations on Hainan's Environmental Protection, Jiangsu's Temporal Methods on $\mathrm{CO}_{2}$ Emission Trading, Taiyuan's Administration Methods on $\mathrm{CO}_{2}$ Emission Trading issued in 1990; the implementation scheme for The Experiment Plan for the Emission Trading of Thermal Power Plants in Pearl River Delta in 2007; Jiangsu's Methods for Paid Use of $\mathrm{SO}_{2}$ Emission Quotas (Trial) and so on. Although the emission trading policies in some local regulations are not applied to practical implementation and the effects are to be observed, they have offered valuable lessons for the establishment of 
emission trading system in China. At the national level, the State Council approved of $A$ Control Plan for the Volume of Major Emissions during the Nineth Five-Year Plan in 1996. In 2000, the legislative status of the volume control plan got established in Air Pollution Prevention and Control in People's Republic of China (Revised Edition) approved of by NPC and Rules for the Implementation of Water Pollution Prevention and Control in People's Republic of China. In Management Regulation of Emission Fee Collection and Usage issued in 2003, there were some changes in the fee collection standards from the former standards to new ones based on the type and quantity of pollutants which involve the coexistence of regular charges and charges for extra parts. This adjustment has been adapted to the conversion in the way of thinking in China's prevention and control of pollution, that is, converting from the control of the density of pollutants to the combination of volume and density control.

\subsection{Practice in Emission Trading}

Emission trading has achieved success to some degree in China. Since mid 1980s, pilot projects have been established in many Chinese cities. For example, in 1987, Environmental Protection Agency in Minhang District of Shanghai began to conduct its emission trading pilot project and laid down corresponding administration methods in terms of the confirmation of emission, emission trading procedures and emission trading fee. Ever since 1991, some trials in air pollution emission trading have been conducted in Baotou, Liuzhou, Taiyuan, Pingdingshan and Guiyang; emission trading system began to be employed in September 2001. At the conference on the pilot project of $\mathrm{SO}_{2}$ emission trading in seven provinces including Shandong, Shanxi, Jiangsu, Henan, Shanghai, Tianjin, Liuzhou and so on, specific stages and implementation schemes on the pilot project of emission trading were clarified. At the end of 2007, the first domestic emission reserve trading center was established in Jiaxing of Zhejiang Province, which conducted some trials in air and water emission trading. By March 2009, the emission trading volume in Jiaxing had exceeded 110,000,000 yuan. In August 2008, the first initiative in the paid use and trading of emission was conducted in Taihu Basin, earning a legislative status for emission trading policies for the first time. Meanwhile, Environmental trading institutions have mushroomed with the establishment of Shanghai Environmental Resources Trading Agency and Beiging Environmental Resources Trading Agency. At the end of 2008, the application for the establishment of an emission trading agency in Binhai of Tianjin was approved of. Up to now, a lot of provinces and cities including Hubei, Wuhan and Heilongjiang have raised a claim to establish environmental ownership trading agencies, burning the issue of emission trading to the torch.

\section{Difficulties in China's Emission Trading System}

\subsection{Environmental Capacity and Value Determination}

Environmental capacity should be confirmed, evaluated and estimated scientifically at the very beginning of emission trading. As the basis for enterprises' allocated emission quotas, the emission volume in a region should be based on its local environmental capacity, which, however, involves too many uncertain factors, hence taking a long and complicated process for precise evaluation. Otherwise, some negative effects may be caused by excessive or insufficient evaluation. In practice, emission trading is not centered on volume control. Some areas just confirm their emission volume according to the macro environment of the nation, which fails to achieve the goal of pollutant control completely in spite of the success in solving the issue of emission trading superficially.

\subsection{The Allocation of Emission}

Currently, allocation methods can be divided into government's free allocation and paid allocation. The latter achieves Pareto optimum through market competition by holding auctions after government sets a price while the former is conducted through government's distribution of licenses. For some old enterprises, emission is free, but some newly-established ones have to pay for it. As a result, unfair treatment arises in the allocation of emission quotas, hence preventing more effective allocation of emission quotas.

\subsection{Establishment and Operation of Market System}

The key to the implementation of emission trading system lies in the establishment and effective formation of trading. Currently, China's practice in this aspect stays at a preliminary level. On one hand, the trading market seems to be dull and enterprises have no passion for that. A majority of transactions are implemented through the relations between government and environmental protection agencies, hence failing to exert the power of market from information offering to a series of verifications. On the other hand, once converted into a valuable property, emission falls into the commodity category. With its entry, this special commodity will surely follow the step of market economy rules. During this process, the purchase of commodities or securities in anticipation of a rise in prices tends to occur and some enterprises prefer to retain their surplus emission volume for later use in 
expanded production, which is also a problem left for the government to integrate and supervise emission trading. In a word, market construction hasn't been fully completed, leading to the failure in exerting the independence and flexibility of market economy.

\subsection{Legislation and Enforcement}

Currently, in some Chinese provinces and cities are established some administrative regulations on emission trading with local characteristics. However, there is still no emission trading regulations with greater adaptability to clearly lay down a variety of working rules. Without relevant laws and regulations, some problems may be caused, such as insufficient evidence for execution, difficulty in managing affairs according to law as well as in supervision.

\section{Countermeasures to Perfect China's Emission Trading System}

\subsection{Precisely Measuring Actual Environmental Capacity}

Emission trading starts with and aims at volume control. In emission trading, environmental capacity should be confirmed, evaluated and calculated scientifically. Government management institutions are expected to confirm the permitted pollutant emission volume, that is, environmental capacity, according to the environmental quality standard of the target control point as well as the dispersal pattern of pollutants. Since environmental capacity is traded as a resource in emission trading process, it needs to be valued. But actually, it is quite complicated and rough to confirm environmental capacity. As a result, relevant environmental administration departments and scientific research institutions are expected to overcome difficulties to conduct a large amount of concrete and careful work related to the innovation and investigation of basic theories and methods.

\subsection{Perfecting Market System for Emission Trading}

The emission trading market can be divided into the first-class market and the second-class market. The first-class market deals with the transaction between government and the emission discharger, that is, the initial allocation process of emission. Generally speaking, emission can be offered freely or at a low price to those dischargers responsible for public affairs and having small amount of emission. However, for those profit-making enterprises with considerable pollutant discharge, emission should be given through auctions or other market forms. The second-class market refers to the transaction place among pollutant dischargers, hence the critical section in the achievement of emission's optimized allocation. Since China's second-class market is largely influenced by traditional planned economy, greater efforts should be made to exert the coordinative role of market economy. Based on pilot projects as well as practical experiences, trading markets should be actively developed, fair and reasonable initial allocation of emission should be explored and fair trading system and special emission trading market should be established to guarantee the sound development of emission trading, to compensate for some possible deficiencies in market trading and to provide a favorable platform for enterprises' transactions. When establishing and promoting market-based emission, it is of particular importance to reform the current management system on emission, through which market economy rules can be applied to emission management effectively, creating a favorable atmosphere for market-based emission.

\subsection{Perfecting Laws and Regulations on Emission Trading}

Since emission trading is based on market economy and environmental capacity as a resource, only with perfect laws and regulations on emission trading and supporting system will the legality of emission, the justice of emission allocation and the legality of emission trading be guaranteed, hence ensuring enterprises' free transaction and information share at the emission trading market and promoting fair market competition.

Government is expected to include emission trading system in Environmental Law, in which it is confirmed in the legal form that environment is an applicable resource. Meanwhile, corresponding local government or departments responsible for environmental protection are supposed to lay down specific operation rules to effectively promote the control over pollutant emission volume as well as the improvement of environmental quality. In order to guide, standardize, maintain and monitor emission trading, local legislation should also be strengthened and perfected in experiment places of emission trading, based on which efforts should be made to sum up lessons and to establish department rules in order to strengthen the guidance and coordination of the nationwide emission trading. At the same time, legislative interpretation made by NPC should be enhanced and laws should be amended to construct a legal basis for emission trading. The collective ownership of surplus environmental capacity resources should be confirmed through NPC's legislative interpretation. In administrative legislation and local legislation, paid use of initial emission allocation should be established according to the collective ownership of environmental capacity resources. In addition, all units and individuals should be endowed with the obligation to protect and improve environment, prevent and control environmental 
pollution and destruction.

\subsection{Strengthening Government's Supervision on Emission Trading}

Government, the impeller of the entire emission trading system, is expected to exert all possible means to guarantee enterprises' orderly production, emission and emission trading and therefore to guarantee the effective implementation of emission trading.

First, during the implementation of emission trading, government should supervise enterprises' behavior. Therefore, rule-violating emission should be severely punished to increase enterprises' cost for violating rules related to environment. Government should establish a set of scientific environmental monitoring standards and supporting advanced monitoring facilities. In addition, environmental supervision departments should be forbidden to force enterprises to be equipped with specific businesses' environmental monitoring products. Market biddings should remain open, competitive and orderly.

Second, government function should be converted to exert it actively and reasonably. With the development of emission trading system in China, government function has to be converted from a dominator of emission quota distribution to a supervisor and protector of emission market trading. In its monitor and management, government should employ more economic methods instead of administrative orders.

\subsection{Developing Emission Trading According to Actual Ability}

Emission trading asks more for management ability and basic facilities. For those areas with poor management and policy execution, emission trading seems unsuitable, otherwise the issues on efficiency and justice may arouse conflicting psychology of pollutant discharging enterprises and therefore fail to achieve the expected effects. For those underdeveloped areas with imperfect automatic monitor system and poor environmental monitor hardware, paid use and trading of emission shouldn't be implemented as well, otherwise enterprises have to resort to illegal discharge in order to avoid increased economic burdens. It is the most important thing for them to improve their environmental management ability, strengthen their basic ability construction based on their reality and employ other environmental management means to achieve their goals before they have got sufficient conditions. Emission trading policy is a double-edged sword in environmental management, which will be the icing on the cake if used properly while adding insult to injury if used improperly. In addition, it is not the only means to have environmental management.

\section{References}

Bi, Jun \& Ye, Weili. (2009). Emission Trading: A Double-edged Sword in Environmental Management. China Report. May $16^{\text {th }}$.

Chang, Jiang \& Wang, Zhongmin. (2010). Difficulties and Environmental Problems in China's Current Emission Trading. Guangming Daily. March $16^{\text {th }}$.

Kong, Guorong \& Lu, Dongfeng. (2008). On China's Emission Trading System. Corporate Economy. (12): pp187-189.

Tian, Lihong. (2008). A Research on China's Emission Trading System. Wuhan: Huazhong Normal University. 5: pp 23-33.

Tietenberg, Tom \& Cui, Weiguo (translator). (1992). Emission Trading: Reform in Pollution Control Policy. Beijing: Sdxjoint Publishing Company. p 214. 